\title{
Explorando a interface entre a antropologia e a genética
}

\author{
Exploring the interface between \\ Anthropology and Genetics
}

\author{
Sérgio D. J. Pena \\ Professor do Departamento de Bioquímica e Imunologia \\ da Universidade Federal de Minas Gerais \\ Av. Antonio Carlos, 6627 \\ 31270-901 Belo Horizonte - MG Brasil \\ spena@dcc.ufmg.br
}

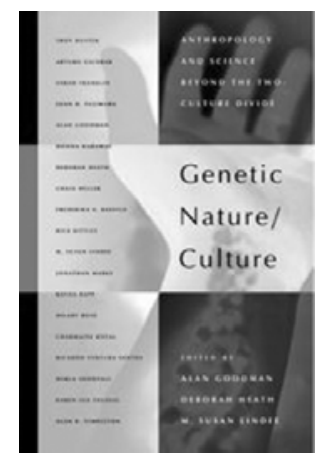

Alan H. Goodman, Debora Heath e M. Susan Lindee (eds.) Genetic nature/culture: Anthropology and science beyond the twoculture divide.

University of California Press, Berkeley/Los Angeles/Londres, 2003, 328p.
$\mathrm{E}$ sta coletânea é produto de uma conferência que ocorreu em 1999 em Teresópolis, RJ, intitulada 'Anthropology in the age of genetics: practice, discourse, critique', que é também o título do artigo introdutório escrito pelos organizadores. Os 14 outros textos, distribuídos em 311 páginas, versam sobre assuntos variados, analisando o impacto que os avanços da genética humana tiveram sobre a antropologia e apossando-se da própria genética humana, incluindo os geneticistas, como nova e rica área de investigação.

Talvez porque eu seja médico geneticista e não antropólogo, confesso que achei as repetidas referências (no prefácio, na introdução e no título do livro às "duas culturas" de C. P. Snow um pouco cansativas. Acredito que o ambiente intelectual e científico atual é bem diferente do final da década de 1950 quando Snow (1959) proferiu sua famosa 'Rede Lecture'. Atualmente há um diálogo muito maior entre os dois 'compartimentos' (ciências experimentais vs ciências humanas) e este livro é prova disso. Como mencionado em algum ponto do mesmo, tem ocorrido uma crescente 'antropologização' da genética, assim como uma correspondente 'geneticização' da antropologia, de maneira que o diálogo hoje é possível e fértil. Por que então chamar a atenção para este (decrescente) dualismo? Por que enfatizar conflitos e diferenças ao invés de compatibilidades e semelhanças? Charlie Chan, o famoso detetive sino-havaiano dos filmes das décadas de 1930 e 1940, dizia, em um dos seus famosos aforismos, que a mente é igual ao pára-quedas: funciona melhor aberta. Não sei se os coordenadores da conferência estavam com a mente aberta, dispostos a aprender com os próprios palestrantes, ou se eles já vieram com a idéia preconcebida de que os geneticistas são reducionistas, deterministas, míopes e obcecados em obter as amostras necessárias para seus experimentos a qualquer custo.

Felizmente, os conceitos e preconceitos dos coordenadores não contaminaram os colaboradores, que escreveram excelentes trabalhos o volume é muito bem-sucedido em apresentar um amplo panorama da visão social e bioética de vários dos principais projetos da genética moderna. Começando com o pé direito, o primeiro artigo é uma interessante e bem escrita discussão conduzida por Ricardo Ventura Santos do contraste entre a pesquisa genética de ameríndios da Amazônia, realizada por James Neel nas décadas de 1960 e 1970, e o malfadado Projeto de Diversidade Genética Humana, comandado por Luca Cavalli- 
Sforza na década de 1990. Foi uma sorte o texto ter sido escrito antes da publicação do livro Darkness in Eldorado, no qual Patrick Tierney (2000) difama James Neel, porque senão seria interpretado como uma reação ao mesmo. Desta maneira, ficou como uma homenagem espontânea a um grande geneticista.

Os dois artigos seguintes lidam com duas comunidades: os Amish da Pennsylvania e os membros da organização Little People of America. Com relação aos Amish, M. Susan Lindee descreve os trabalhos que Victor McKusick, grande médico-geneticista da Universidade Johns Hopkins, em Baltimore, realizou nesta comunidade religiosa isolada, especialmente o levantamento genealógico com relação à síndrome de Ellis-van Creveld, uma forma autossômica recessiva de nanismo. A autora registra um traço marcante no trabalho de McKusick, que ela denomina de cataloguing imperative, e chama atenção para a sua consonância com o Projeto Genoma Humano. Na verdade, Victor McKusick, com o seu catálogo de doenças mendelianas humanas é reconhecidamente um dos pais intelectuais do Projeto Genoma Humano. Muito depois dos trabalhos com os Amish, ele viria a ser o primeiro presidente da Human Genome Organization (HUGO) e editor do periódico 'oficial' do projeto, cujo título é um neologismo cunhado por ele: Genomics. O trabalho de Victor McKusick com a síndrome de Ellis van Creveld nos Amish e seu esforço nosológico de catalogar as doenças de herança mendeliana, associadas com baixa estatura em humanos, foram fundamentais para o estabelecimento e o sucesso do grupo de ajuda mútua Little People of América (LPA), que constitui o foco do terceiro artigo, escrito por Karen-Sue Taussig, Rayna Rapp e Deborah Heath. É uma pena que o nome de Victor McKusick (que era membro honorário vitalício da organização apesar de sua alta estatura, considerada inflacionária pelos membros do LPA) não seja sequer mencionado neste texto. Aliás, nota-se aqui justamente uma deficiência da obra: a ausência de 'pontes' entre as diferentes contribuições, o que constitui uma das partes mais difíceis (e negligenciadas) da coordenação de um livro multi-autorado.

O quarto artigo, escrito por Hilary Rose, discute a controvertida empresa deCode Genetics criada na Islândia pelo imunologista Kari Stefansson. Esta empresa, com autorização do governo islandês, criou um imenso banco de dados clínicos e de DNA de toda a população deste país-ilha com menos de trezentos mil habitantes, onde a genealogia é uma paixão. A deCode agora está negociando o acesso a este banco de dados com companhias farmacêuticas, em troca de promessa de que no futuro haverá o acesso gratuito aos fármacos desenvolvidos com o uso destes dados.

Segue-se um artigo que contém uma interessante abordagem feita por Sarah Franklin envolvendo alguns tópicos éticos em torno da clonagem animal, especialmente em termos de parentesco, genes e biologia. O sexto artigo, escrito com humor e sensibilidade por Donna Haraway, descreve "o mundo da genética (e genômica) canina". O cão é uma espécie que coevoluiu por milhares de anos com o homem, sendo neste processo o objeto experimental de um fabuloso programa de seleção artificial conduzido através de cruzamentos programados 
(e absolutamente empíricos), cujos resultados só bem recentemente foram analisados do ponto de vista genômico (Parker et al. 2004).

Em seguida, vem um artigo de Jonathan Marks (2002), poeticamente intitulado, ' $98 \%$ chimpanzee and $35 \%$ daffodil', em que discute o significado evolucionário e filosófico da semelhança genômica entre o homem e os outros seres vivos, em especial com os outros primatas. Este texto é uma severa crítica do enfoque genomocêntrico preconizado por alguns na biologia moderna, e ao mesmo tempo um excelente sumário do livro que o autor publicou com título muito semelhante em 2002. A conclusão é que a similaridade entre o genoma humano e o de outros seres vivos "é interessante, mas não é profunda". Continuando a varredura de tópicos socialmente relevantes, o artigo seguinte aborda uma problemática aguda e momentânea no Brasil: os organismos geneticamente modificados. Os autores, Chaia Heller e Arturo Escobar, discutem aspectos variados do problema, como biodiversidade, política ecológica e biotecnologia. Uma boa leitura em época de aprovação da Lei de Biossegurança pelo Congresso Nacional.

Seguem-se dois artigos abordando temas de interesse mais regional: um sobre a importância da genômica no Japão, com suas implicações de modernidade e ocidentalização cultural, e o outro fazendo uma descrição do panorama da genética antropológica na África do Sul.

Finalmente, os quatro últimos artigos são organizados em torno de um dos meus temas favoritos: 'race and human variation'. Aqui, confesso que fiquei um pouco despontado, pois esperava mais. Tanto o texto de Rick Kittles e Charmaine Royal, sobre 'The genetics of African Americans', quanto o artigo de Fredrica Kaestle, discutindo estudos em DNA arqueológico humano, me pareceram demasiadamente superficiais para a importância e a riqueza dos seus temas. Uma jóia entre esses artigos é o de Alan Templeton descrevendo e fazendo a partição dos padrões continentais da variabilidade humana. A conclusão, baseada no baixo nível de diferenciação genética das populações humanas, é que o conceito de raças humanas é geneticamente indefensável e biologicamente enganoso. Esta temática é importantíssima, mas infelizmente não é novidade, pois o mesmo autor desenvolveu exatamente o mesmo raciocínio no seu já clássico artigo publicado em 1999 no periódico American Anthropologist (1999, p. 632-650). O texto subseqüente, no livro ora resenhado, escrito por Troy Duster, intitulase 'Buried alive: the concept of race in science'. É um enigma e está totalmente fora de sintonia com o espírito do livro e dos outros autores, especialmente de Alan Templeton. Duster, nada modestamente, afirma logo de saída que "In this essay, I demonstrate how and why purging science of races (...) is not practicable, possible or even desirable". A verdade é que ele não consegue demonstrar o indemonstrável. O texto me fez lembrar a frase de Paul Gilroy (2000) em seu excelente livro Against race: "It is therefore disappointing that much influential recent work in this area loses its nerve in the final furlong and opts to remain ambiguous about whether the Idea of 'race' can survive a critical revision of the relationship between human beings and their constantly shifting social nature".

Em resumo, este livro apresenta uma boa revisão dos temas importantes na interface entre a genética e a antropologia. Embora a quali- 
dade das contribuições seja um pouco irregular, a maioria deles é informativa e bem escrita. Caveat emptor: já se passaram cinco anos desde a conferência que deu origem ao livro. Conseqüentemente, alguns textos estão desatualizados, tendo sido superados, em alguns casos, por outras publicações dos próprios autores.

\section{REFERÊNCIAS BIBLIOGRÁFICAS}

Gilroy, $\mathrm{P}$.

2000

Against race: imagining political culture beyond the color line.

Cambridge, Harvard University Press.

Marks, J.

2002

What it means to be 98\% chimpanzee: apes, people and their genes.

Berkeley, University of California Press.

Parker, H. G. et al. 2004

Genetic structure of the purebred domestic dog. Science, v. 304, p. 1160-4.

Snow, C. P. The two cultures.

Cambridge, Cambridge University Press.

Templeton, A. R. 1999

Tierney, P. 2000
Human races: a genetic and evolutionary perspective. Am. Anthropol., v. 100, p. 632-50.

Darkness in El Dorado: how scientists and journalists devastated the Amazon. New York, W. W. Norton.

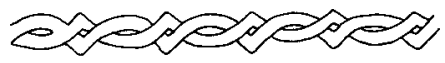

